\title{
Comparative study between intrapolyp steroid injection and oral steroid for treatment of sinonasal polyposis in Egyptian patients
}

\author{
Sameh M. Zamzam * (D), Mohamed Elshazly, Mohamed Salah and Abdallah Enayat
}

\begin{abstract}
Background: Management of patients with sinonasal polyps ranges from systemic steroid to functional endoscopic sinus surgery; however, many patients refuse surgery or are contraindicated to receive systemic steroid. Intrapolyp steroid injection has been recently used to apply a higher concentration of steroids into the nasal polyps and on the other hand protecting the patient from the side effects of systemic steroid. In this study, we have tested intrapolyp steroid injection on 22 patients (injection group) and the results were statistically compared with the results of 16 patients treated by oral steroid (oral group) subjectively by total nasal symptoms score and objectively by total nasal polyp score and on CT films by using Lund Mackay scoring system, patients of both groups have been followed up for 3 months.
\end{abstract}

Results: After treatment, there was a statistically significant decrease in the score in both groups, with no significant difference in between them. No serious complications as visual disturbance apart from mild self-limited bleeding detected in only 2 injections (3\%) of all 66 injections.

Conclusion: Intrapolyp steroid injection is an effective, easy, and safe procedure with short-lasting effect for at least 3 months. It was proven to show comparable results to oral steroids as both modalities showed a statistically significant improvement subjectively and objectively. However, cases with extensive bulky polyposis were resistant to complete eradication by injection and they may need surgical intervention.

Keywords: Sinonasal polyps, Intrapolyp injection, Steroid, Triamcinolone acetonide

\section{Background}

Management of sinonasal polyposis clues range from topical and systemic steroids to functional endoscopic sinus surgery [1]. Topical intranasal steroid sprays, even it has a wide range of usage but sometimes do not succeed to provide cure and can be associated with a nasal septal perforation [2]. Using systemic steroid in the treatment of sinonasal polyposis carries the risk of systemic side effects [3]. Intrapolyp steroid injections have been recently used to apply a higher

\footnotetext{
* Correspondence: samehzamzam@hotmail.com

ENT Department, Kasr Alainy Hospital, Garden City, Cairo, Egypt
}

concentration of steroid into the nasal polyps while at the same time protecting the patient from the side effects of systemic steroid [4]. This study aimed to study and evaluate the efficacy and safety of intrapolyp steroid injection in the treatment of sinonasal polyposis, comparing these results with that of oral steroid.

\section{Methods}

A comparative prospective study was conducted on 38 patients. Twenty males and 18 females with age range 28-65 and mean +/-SD $42+/-18$ years old. This study included all patients diagnosed with nasal

\section{Springer Open}

() The Author(s). 2020 Open Access This article is licensed under a Creative Commons Attribution 4.0 International License, which permits use, sharing, adaptation, distribution and reproduction in any medium or format, as long as you give appropriate credit to the original author(s) and the source, provide a link to the Creative Commons licence, and indicate if changes were made. The images or other third party material in this article are included in the article's Creative Commons licence, unless indicated otherwise in a credit line to the material. If material is not included in the article's Creative Commons licence and your intended use is not permitted by statutory regulation or exceeds the permitted use, you will need to obtain permission directly from the copyright holder. To view a copy of this licence, visit http://creativecommons.org/licenses/by/4.0/. 
Table 1 Total nasal symptoms score (TNSS) and total nasal polyps score (TNPS) in both groups before receiving treatment

\begin{tabular}{|c|c|c|c|c|c|c|c|}
\hline \multirow{2}{*}{$\begin{array}{l}\text { Pre- } \\
\text { treatment }\end{array}$} & \multicolumn{3}{|c|}{ Oral steroids group } & \multicolumn{3}{|c|}{ Injection group } & \multirow{2}{*}{$\begin{array}{l}P \\
\text { value }\end{array}$} \\
\hline & Mean & SD & Median & Mean & SD & Median & \\
\hline TNSS & 17.00 & 4.59 & 17.00 & 18.74 & 4.04 & 18.00 & 0.193 \\
\hline TNPS & 4.90 & 1.24 & 5.00 & 4.67 & 1.59 & 6.00 & 0.838 \\
\hline
\end{tabular}

polyposis and excluded patients with fungal polyps, cystic fibrosis, any patients contraindicated to receive steroid, patients with previous trial of medical or surgical treatment of nasal polyposis, and patients with locoregional complications like hypertelorism or proptosis. Patients presented to the ENT outpatient clinic at (Cairo University Hospitals) from October 2016 to January 2017. Twenty-two patients (11 males and 11 females) were treated by intrapolyp injection of steroid and 16 patients (9 males and 7 females) were treated by oral steroid.

\section{Technique}

- In the injection group (22 patients)

- One milliliter of triamcinolone acetonide $40 \mathrm{mg}$ was injected using $3 \mathrm{ml}$ syringe and 21 gage needle or larger.

- Cotton pieces impregnated in a mixture of equivalent amount of $4 \%$ lidocaine and $0.05 \%$ oxymetazoline then packed into the nasal cavity for $10 \mathrm{~min}$.

- The triamcinolone acetonide syringe was shaken vigorously to dissolve the whole particles of the drug.

- The triamcinolone was injected into the polyp with depth of 1-2 mm using 0-degree endoscope.

- The $1 \mathrm{ml}$ of triamcinolone was injected inside all polyps per side.

- All the patients have received injections bilaterally. The patients returned at a week interval till they completed a series of 3 injections.

- A total of 66 injections were administrated in 22 patients. Each has received $80 \mathrm{mg}$ per both sides per time.

- In the oral group (16 patients)

Table 2 Total nasal symptoms score (TNSS) and total nasal polyps score (TNPS) in both groups after receiving treatment

\begin{tabular}{|c|c|c|c|c|c|c|c|}
\hline \multirow[t]{2}{*}{ Post-treatment } & \multicolumn{3}{|c|}{ Oral steroids group } & \multicolumn{3}{|c|}{ Injection group } & \multirow{2}{*}{$\begin{array}{l}P \\
\text { value }\end{array}$} \\
\hline & Mean & SD & Median & Mean & SD & Median & \\
\hline TNSS & 8.30 & 5.12 & 8.00 & 10.89 & 4.62 & 9.00 & 0.006 \\
\hline TNPS & 2.60 & 2.04 & 2.00 & 3.33 & 1.82 & 4.00 & 0.146 \\
\hline
\end{tabular}

Table 3 Total nasal symptoms score (TNSS) before and after treatment in the injection group

\begin{tabular}{|c|c|c|c|c|c|c|c|}
\hline \multirow[t]{2}{*}{ Symptom } & \multicolumn{3}{|c|}{ Before treatment } & \multicolumn{3}{|c|}{ After treatment } & \multirow[t]{2}{*}{$P$ value } \\
\hline & Mean & SD & Median & Mean & SD & Median & \\
\hline 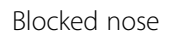 & 5.56 & 0.70 & 6.00 & 19 & 1.75 & 3.00 & $<0.001$ \\
\hline dinty & 5.30 & 0.87 & 6.00 & 3.22 & 1.58 & 2.00 & 0.001 \\
\hline chin & 1.33 & 1.14 & 1.00 & 0.85 & 0.91 & 1.00 & $<0$. \\
\hline heezing & 2.11 & 1.40 & 2.00 & 0.89 & 1.12 & 1.00 & $<0.001$ \\
\hline$y+$ & 4.96 & 1.02 & 5.00 & 5.04 & 1.43 & 3.00 & 0.317 \\
\hline בחת & 0.07 & 0.27 & 0.00 & 0.04 & 0.19 & 0.00 & $<0.001$ \\
\hline NSS & 18.74 & 4.04 & 18.00 & 10.89 & 4.62 & 9.00 & $<0.001$ \\
\hline
\end{tabular}

- The patients received oral prednisolone for 2 weeks starting with dose of $1 \mathrm{mg} / \mathrm{kg} /$ day, and decreasing the dose by $20 \mathrm{mg}$ every 5 days. With an average starting dose of $60 \mathrm{mg}$ for each patient.

- Both groups, patients' symptoms were recorded before and after treatment by using total nasal symptom score (TNSS), endoscopic examination using total nasal polyp score (TNPS), and CT imaging using Lund-Mackay score were used for the assessment.

- Total nasal symptoms score (TNSS): a subjective scoring of clinical disease severity. Patients' symptoms were evaluated based on a questionnaire assessing nasal occlusion, rhinorrhea, sneezing, nasal itching, hyposmia, and sinonasal pain. The severity of each single symptom was assessed with a 7-point scale: $0=$ no symptoms; 1 to $2=$ mild symptoms; 3 to $4=$ moderate symptoms; and 5 to $6=$ severe symptoms. The summation of these nasal symptom scores provided the TNSS which ranges from 0-36

- Total nasal polyp score (TNPS): nasal polyp size was assessed by nasal endoscopy and scored on a 0-3 scale as follows: $0=$ no polyps; $1=$ polyps above level of inferior turbinate; 2 = polyps extended downward to the same level of inferior turbinate; and 3 = severe polyposis extend much more downward to be below the level of inferior turbinate. The total nasal polyps score (TNPS) was calculated as the sum of the polyp scores for each side.

Table 4 Total nasal polyps score (TNPS) before and after treatment in the injection group

\begin{tabular}{|c|c|c|c|c|c|c|c|}
\hline \multirow[t]{2}{*}{ Side } & \multicolumn{3}{|c|}{ Before treatment } & \multicolumn{3}{|c|}{ After treatment } & \multirow[t]{2}{*}{$P$ value } \\
\hline & Mean & SD & Median & Mean & SD & Median & \\
\hline RT side & 2.63 & 0.56 & 3.00 & 1.78 & 1.09 & 2.00 & 0.001 \\
\hline LT side & 2.04 & 1.26 & 3.00 & 1.56 & 1.09 & 2.00 & 0.001 \\
\hline TNPS & 4.67 & 1.59 & 6.00 & 3.33 & 1.82 & 4.00 & $<0.001$ \\
\hline
\end{tabular}


Table 5 Total nasal symptoms score (TNSS) before and after treatment in the oral steroid group

\begin{tabular}{|c|c|c|c|c|c|c|c|}
\hline \multirow[t]{2}{*}{ Symptom } & \multicolumn{3}{|c|}{ Before treatment } & \multicolumn{3}{|c|}{ After treatment } & \multirow[t]{2}{*}{$P$ value } \\
\hline & Mean & SD & $\overline{\text { Median }}$ & Mean & SD & Median & \\
\hline 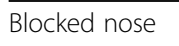 & 5.20 & 1.19 & 0 & 30 & 1.42 & 2.00 & $<0.001$ \\
\hline unny nose & 4.60 & 1.10 & 5.00 & 2.07 & 1.08 & 2.00 & $<0.001$ \\
\hline Itching & 1.27 & 1.11 & 1.00 & 0.83 & 0.83 & 1.00 & 0.00 \\
\hline leezing & 1.77 & 1.36 & 2.00 & 0.83 & 1.12 & 0.50 & $<0.001$ \\
\hline yposmia & 4.63 & 1.00 & 5.00 & 2.33 & 1.47 & 2.00 & $<0.001$ \\
\hline in & 0.13 & 0.35 & 0.00 & 0.00 & 0.00 & 0.00 & 0.046 \\
\hline TNSS & 17.00 & 4.59 & 17.00 & 8.30 & 5.12 & 8.00 & $<0.001$ \\
\hline
\end{tabular}

- Lund-Mackay score (LMS): the CT images of paranasal sinuses were evaluated using LundMackay scoring system. In this system, the right or left group of sinuses were classified into six parts, including maxillary sinus, anterior ethmoid sinuses, posterior ethmoid sinuses, sphenoid sinus, frontal sinus, and osteomeatal complex. The severity of sinus mucosal inflammation or fluid accumulation was scored as 0 (complete opacity), 1 (partial opacity), or 2 (complete opacity). Unilaterally, total LMS values that could range from 0 to 12 , and the LMS of both sides were summed together to give a total score that ranged from 0-24 [5].

All patients were assessed 3 months after both modalities of treatment using TNSS, TNPS, and LMS. Results after 3 months were compared with parameters before starting treatment and results of injection were compared with that of oral steroids.

\section{Result}

The following tables and figures are showing comparison between oral steroid and injection steroid groups regarding TNSS and TNPS and LMS before and after treatment (Tables 1, 2, 3, 4, 5, 6, 7, and 8) (Figs. 1, 2, 3, 4, 5, $6,7,8,9,10,11$, and 12).

No serious complications as hypertension, hyperglycemia, GIT upsets, or mood changes, were reported in the oral steroids group. In the injection group, no serious complications as visual disturbance, severe bleeding, or facial flushing were

Table 6 Total nasal polyps score (TNPS) before and after treatment in the oral steroid group

\begin{tabular}{llllllllll}
\hline Side & \multicolumn{3}{l}{ Before treatment } & & \multicolumn{3}{c}{ After treatment } & \multirow{2}{*}{$\boldsymbol{P}$ value } \\
\cline { 2 - 3 } & Mean & SD & Median & & Mean & SD & Median & \\
\hline RT side & 2.23 & 0.86 & 2.00 & & 1.17 & 1.05 & 1.00 & $<0.001$ \\
LT side & 2.67 & 0.48 & 3.00 & & 1.37 & 1.10 & 1.00 & $<0.001$ \\
TNPS & 4.90 & 1.24 & 5.00 & & 2.60 & 2.04 & 2.00 & $<0.001$ \\
\hline
\end{tabular}

Table 7 Lund-Mackay score before treatment in both groups

\begin{tabular}{|c|c|c|c|c|c|c|c|}
\hline \multirow{2}{*}{$\begin{array}{l}\text { Lund- } \\
\text { Mackay } \\
\text { score }\end{array}$} & \multicolumn{3}{|c|}{ Oral steroids group } & \multicolumn{3}{|c|}{ Injection group } & \multirow{2}{*}{$\begin{array}{l}P \\
\text { value }\end{array}$} \\
\hline & Mean & SD & $\bar{n}$ & n & SD & $n$ & \\
\hline RT side & 10.43 & 1.79 & & & 2 & 10.00 & 0.265 \\
\hline side & 10.60 & 1.71 & 12.00 & 3.07 & 4.67 & 10.00 & 0.075 \\
\hline tal & 20.83 & 3.26 & 21.50 & 17.85 & 6.58 & 20.00 & 0.171 \\
\hline
\end{tabular}

observed apart from minimal self-limited minor bleeding detected in only 2 injections (3\%) of all 66 injections.

\section{Discussion}

Semenov was the first to publish the injection of steroids into sinonasal polyps, followed by Myers, who used prednisolone for intrapolyp injection. In addition, Wall and Shure have been used the same idea but in the treatment of allergic rhinitis by injecting the drug inside the inferior turbinates [6-8]. In the present study, triamcinolone acetonide was used in the injection which was used also in Moss et al.'s study and Kiris et al.'s study, and it is used in intrapolyp injections only in this current study, unlike previously mentioned two studies in which both polyps and turbinates were injected $[4,9]$.

This current study included only patients with sinonasal polyposis, and this is similar to the target population in Semenov's study and Kiris et al.'s study, while in Moss et al.'s study, they included patients with chronic sinusitis with or without polyps. In the earlier studies as Baker and Strauss' study and Simmons et al.'s study, they have included patients with allergic rhinitis, vasomotor rhinitis, and rhinitis medicamentosa [4, 6, 9-11].

In the current study, 66 injections of triamcinolone acetonide in 22 patients out of 38 patients, and each patient in this study received 3 injections compared to Moss et al.'s study, triamcinolone acetonide was used in 237 injections for 78 patients, of which 152 were intraturbinal and 85 were intrapolyp in 25 patients, with average number of 3.5 injections for each patient [9].

In this current study, $72.3 \%$ of the patients in the injection group showed clinical improvement, and almost all of them needed 3 injections for improvement. This is nearly similar to other studies as Moss

\begin{tabular}{|c|c|c|c|c|c|c|c|}
\hline \multirow{2}{*}{$\begin{array}{l}\text { Lund- } \\
\text { Mackay } \\
\text { score }\end{array}$} & \multicolumn{3}{|c|}{ Oral steroids group } & \multicolumn{3}{|c|}{ Injection group } & \multirow{2}{*}{$\begin{array}{l}P \\
\text { value }\end{array}$} \\
\hline & Mean & SD & Median & Mean & SD & Median & \\
\hline RT side & 5.93 & 4.38 & 5.50 & 8.41 & 3.63 & 9.00 & 0.036 \\
\hline LT side & 6.27 & 4.24 & 7.00 & 7.26 & 4.80 & 10.00 & 0.282 \\
\hline Total & 12.67 & 8.38 & 13.50 & 15.48 & 8.60 & 19.00 & 0.167 \\
\hline
\end{tabular}




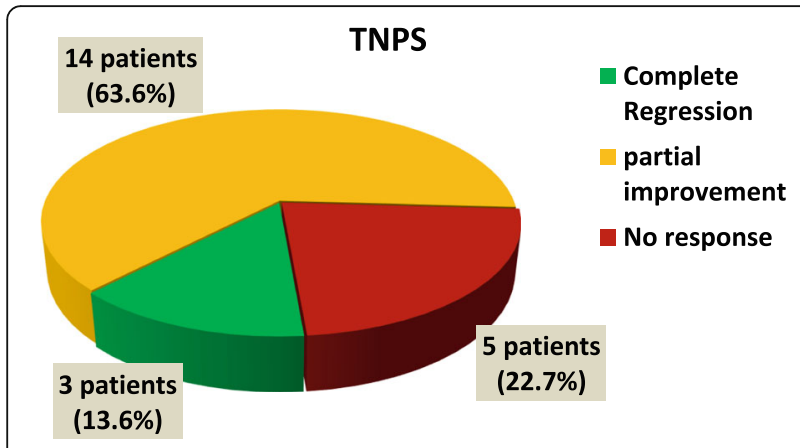

Fig. 1 Pie chart showing the effect of injection on total nasal polyps score (TNPS)

et al.'s study stated that the percentage of patients that reported improvement from injections is $84.5 \%$, and the average number of injections received by them is 3.5 injections. Also, $75 \%$ of patients showed improvement by injections in Baker and Strauss study. In the latter two mentioned studies, assessment of the response to treatment was based subjectively on the relief of complaints without using any scores compared to the current study in which assessment carried out subjectively by using total nasal symptom score and also objectively by using total nasal polyp score and Lund Mackay staging system $[9,10]$.

There are few studies that compared the efficacy of the steroid injection versus oral steroids. One study, Kiris et al.'s, was conducted on 90 patients (compared to 38 in this study), showed that there is significant decrease in TNSS, TNPS, and Lund-Mackay score in approximately $82.2 \%$ of the patients that received injection steroids (compared to $77.3 \%$ of patients in this current study regarding TNPS and $72.3 \%$ regarding Lund-Mackay score), and most patients received 5 injections for improvement with total 211 injections (compared to 3 and 66 injections in the current study), respectively [4].

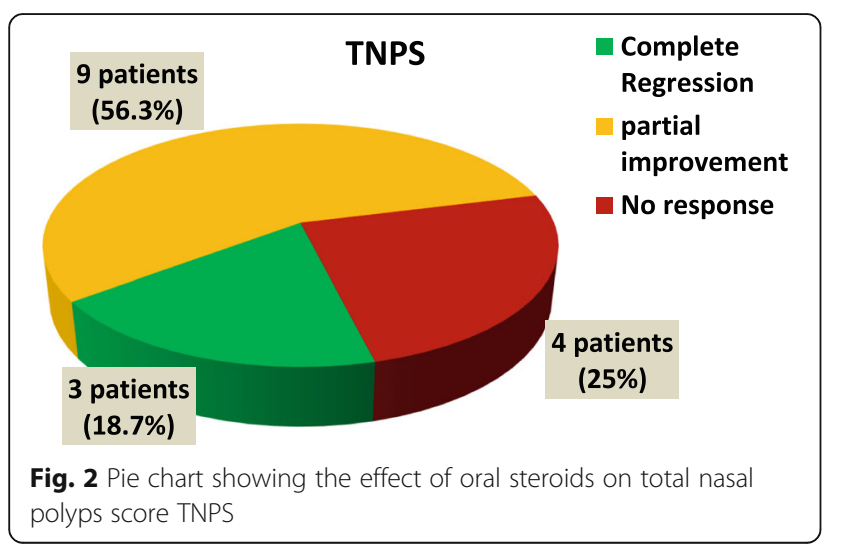

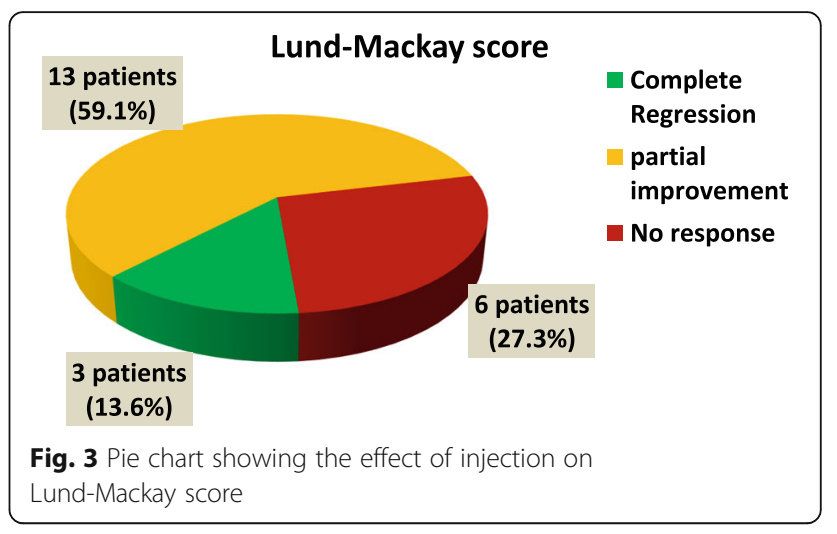

Kiris et al. have found that a slightly higher number of patients improved in the oral steroid group representing $86.7 \%$ of the patients (compared to $75 \%$ in this current study in both TNPS and Lund-Mackay scores). But this difference was not statistically different in both studies [4].

In the current study, the effect of injection on TNPS (showing 77.3\% improvement) slightly differed from its effect on Lund-Mackay score (which showed $72.3 \%$ improvement), while oral steroids exerted the same effect on both scores. This slight difference is thought to be that oral steroids are acting diffusely over nasal polyps as well as nasal mucosa, while injection acts mainly on the polyps more than the nasal mucosa. In Kiris et al. study, this finding was not mentioned as they commented on the percentage of improvement regarding the TNPS only [4].

A study by Ulku et al. was conducted on 17 patients to show the effectiveness of oral steroids in treatment of nasal polyps using symptom and polyp scores, the symptom score differed from that used in this current study but the polyp score was similar, and they found that $12 \%$ of patients disappearance of polyps in the nasal cavity, $76 \%$ a significant decrease of polyps bulk, and $12 \%$ no response to the drug, in a comparable results to this current study in which $18.7 \%$ of the patients were completely free after treatment, $56.3 \%$ showed a clear

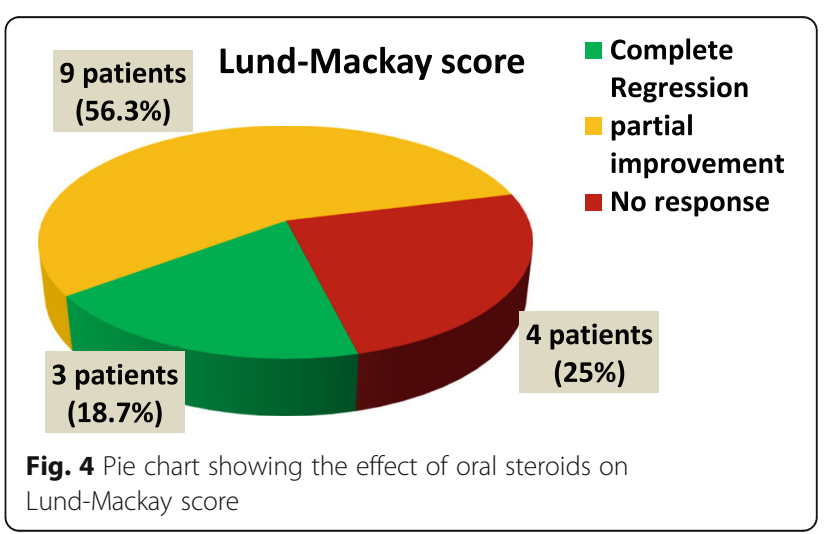



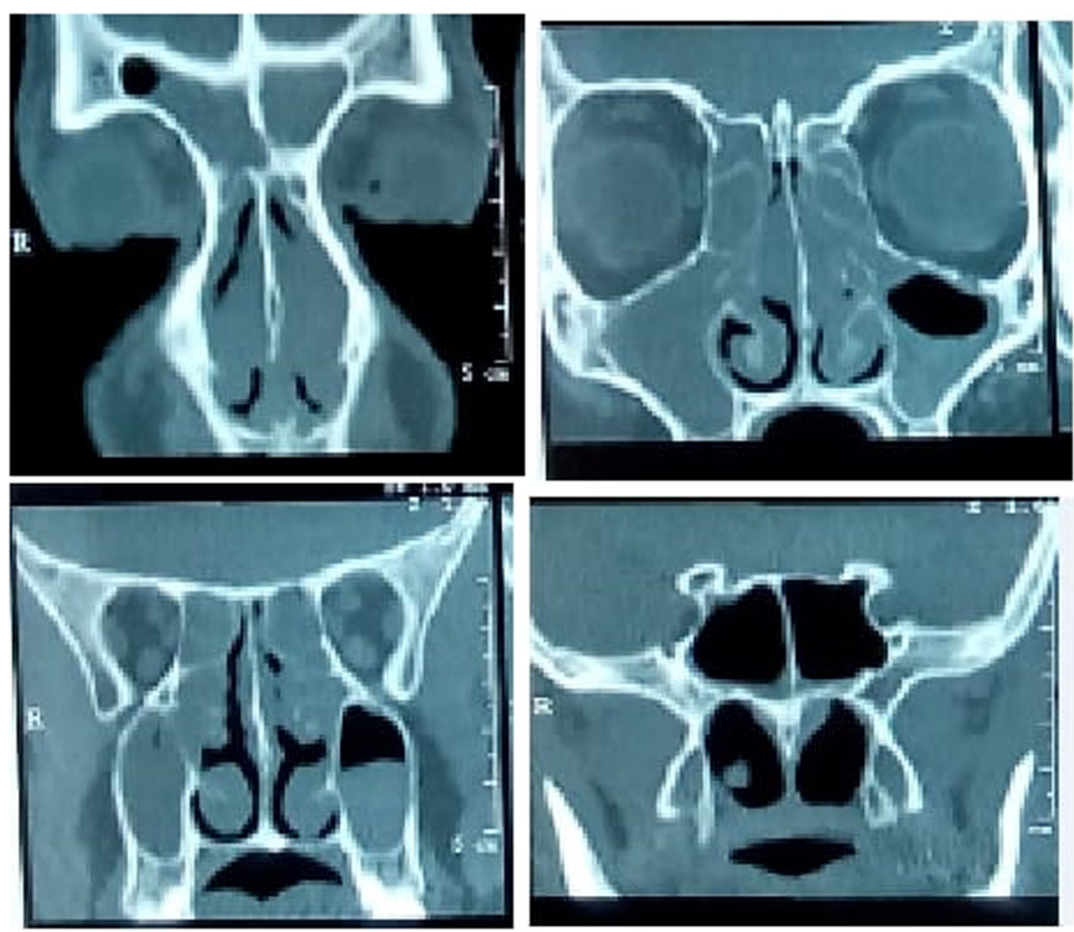

Fig. 5 CT PNS of case from injection group, before treatment
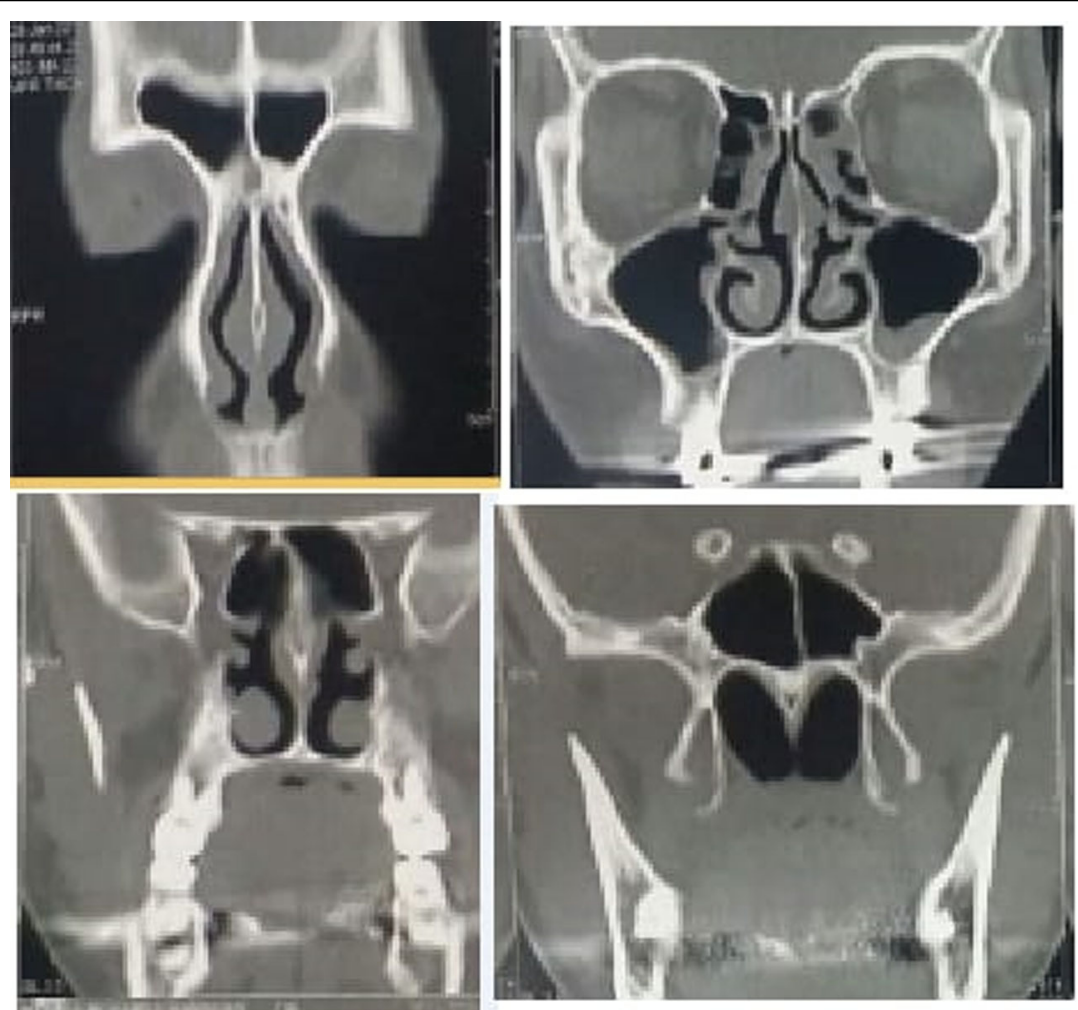

Fig. 6 CT PNS of the same patient after reciveing 3 intrapolyp steroid injection, showing complete regression of nasal polyps 

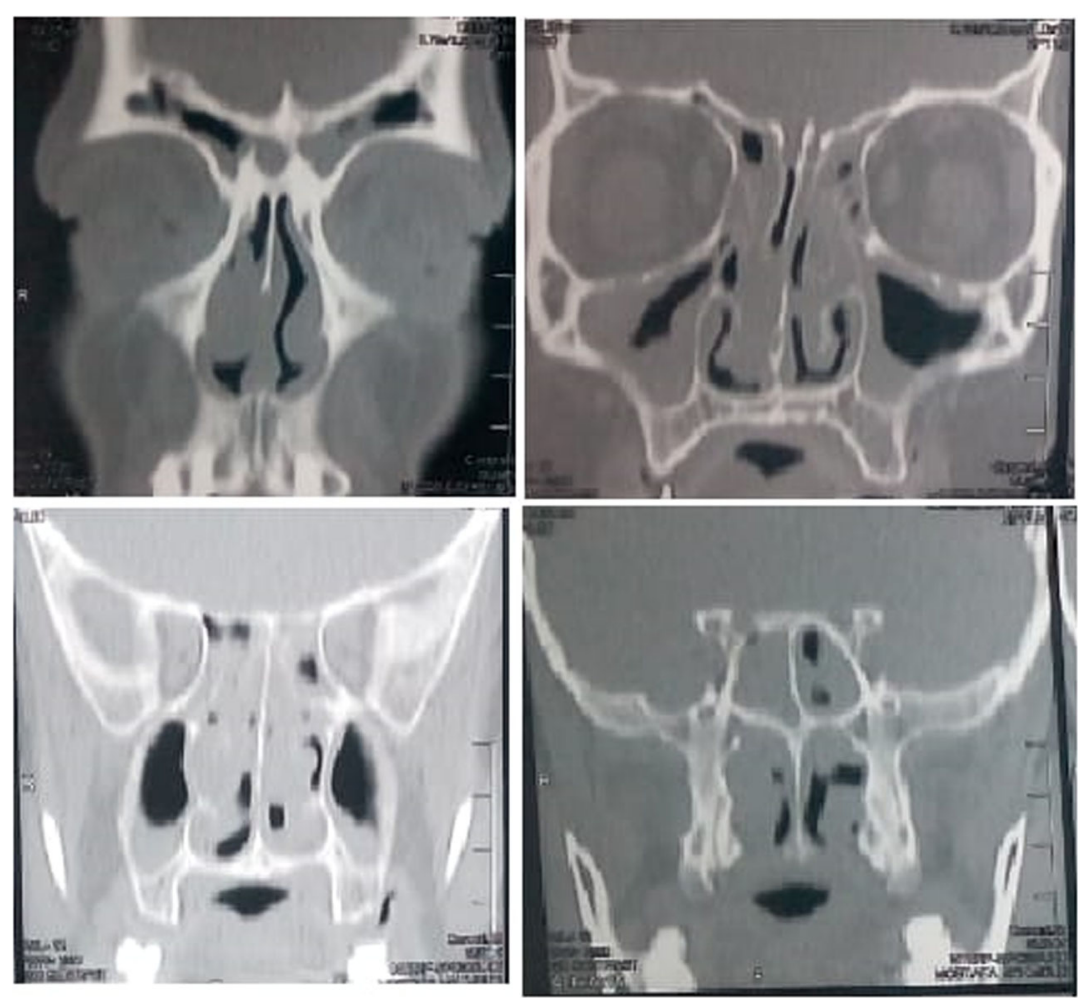

Fig. 7 CT PNS of case from the oral group, before treatment
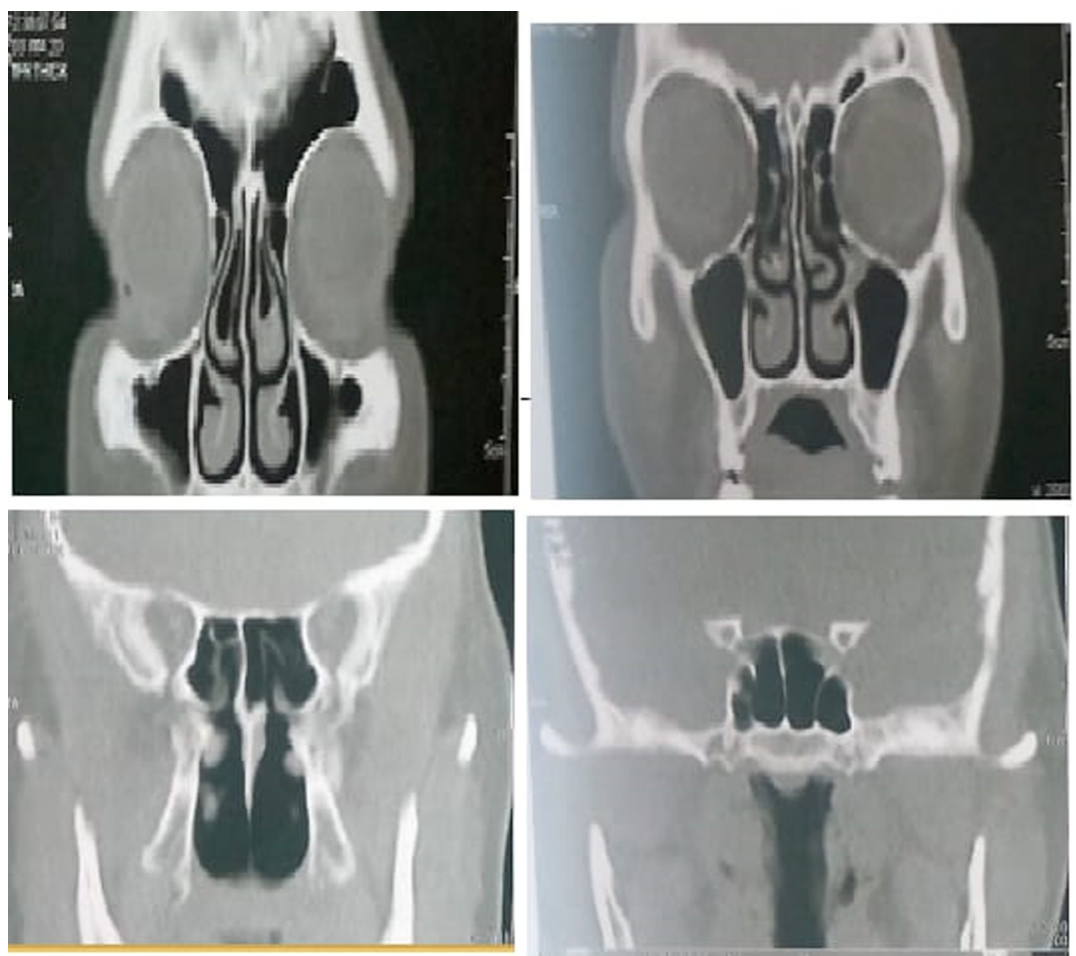

Fig. 8 CT PNS of the same patient after receiving oral steroid, showing complete regression 

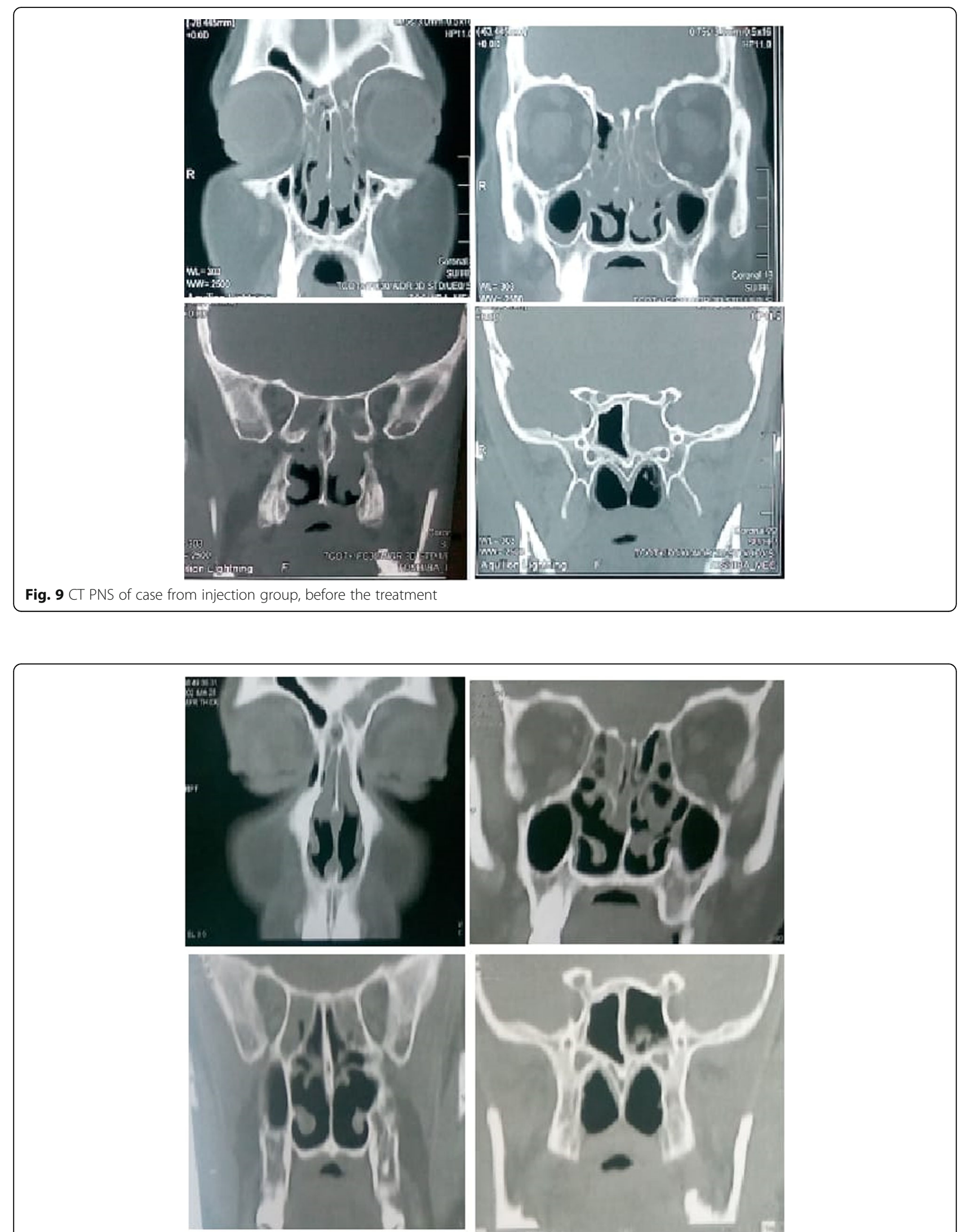

Fig. $10 C T$ PNS of the same patient after 3 intrapolyp steroid injection, showing partial improvement 

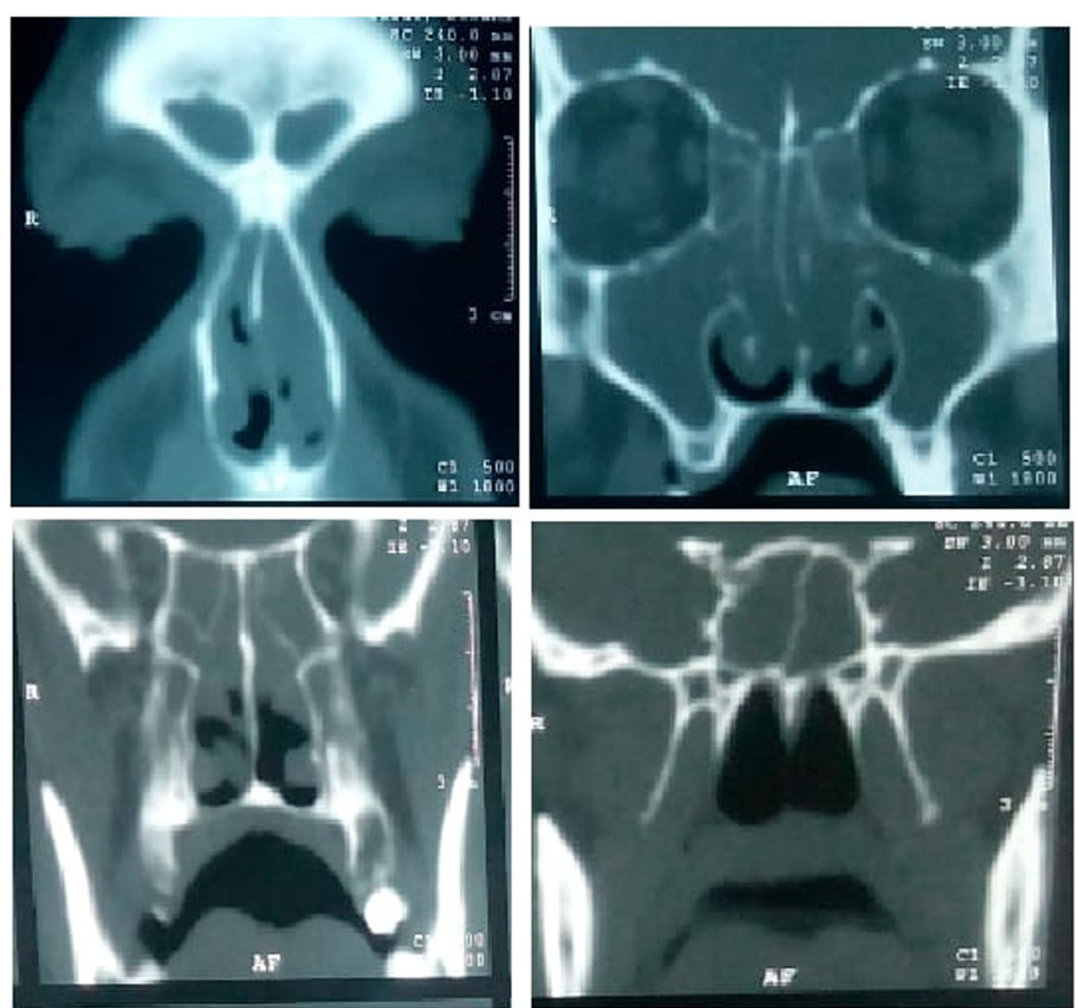

Fig. 11 CT PNS of case from the oral group, before the treatment
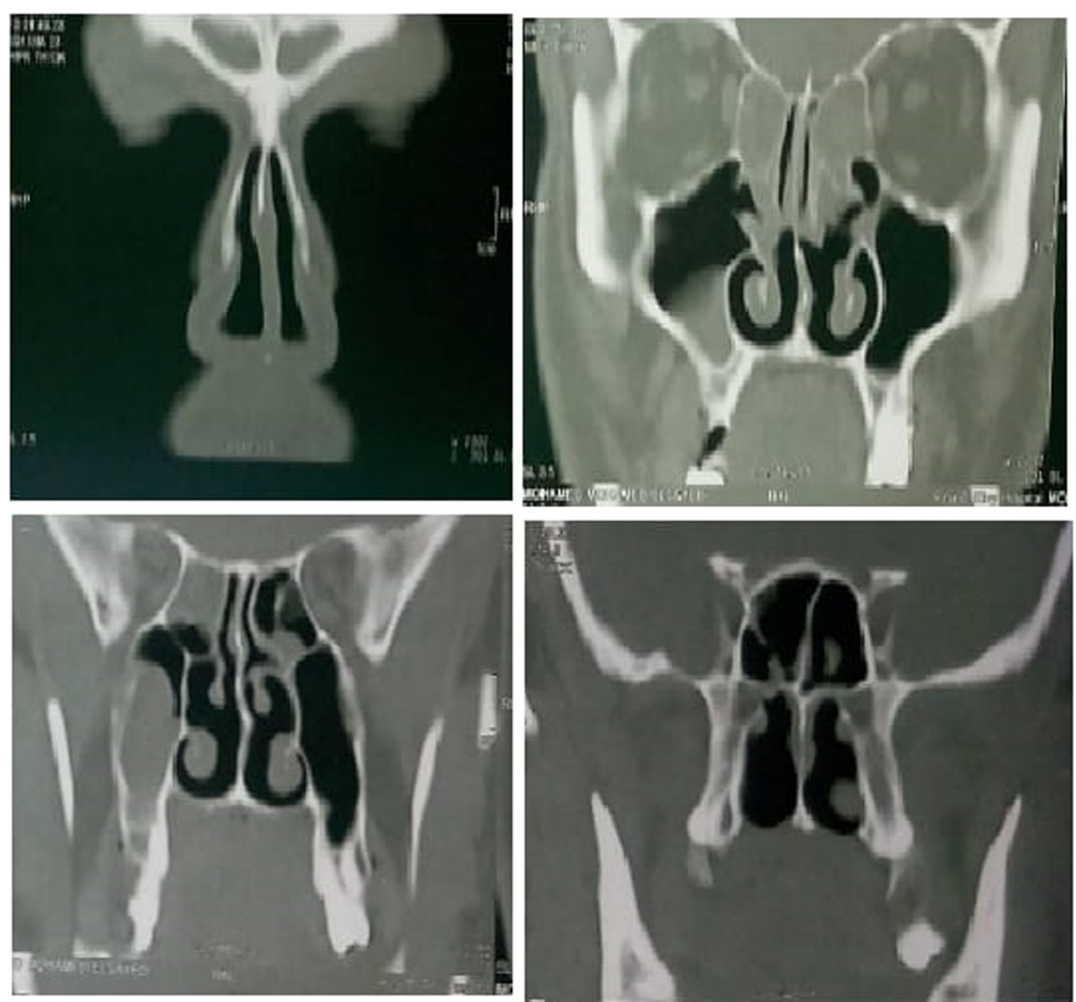

Fig. 12 CT PNS of the same patient after oral steroid, showing partial improvement 
improvement, and $25 \%$ did not show any response at all. In Ulku et al.'s study, they included only patients with sinonasal polyposis, oral prednisolone was used in the dose of $1 \mathrm{mg} / \mathrm{kg} /$ day with gradual tapering over 2 weeks, which was the same in the current study regarding included patients were treated by regimen of the oral steroid [12].

In this current study, we did not detect recurrence during the 3 month follow-up period in both groups, while Kiris et al. and Ulku et al. showed no recurrent cases for at least 6 months and Camp et al. noticed partial recurrence after 5 months of treatment with oral prednisolone. However, the Thibaut et al.'s study has detected $100 \%$ recurrent rate, this may be explained by the small dose of corticosteroids used in the later study [4, 12-14].

We did not observe any serious complications after treatment apart from minor self-limited bleeding was noticed in only 2 injections out of 66 (3\%). Minor bleeding was also seen in 6 out of 211 injections (0.03\%) in Kiris et al.'s study, and $2.1 \%$ in Mabry's study [4, 15]. The first instance of permanent visual loss was reported in 1962 by Hager et al. [16].

Finally, this current study has some limitations. The sample size was relatively small and the time of followup was short, so recurrence beyond 3 months could not be assessed. In addition, comparing injection with local nasal sprays was not evaluated in this study. Another limitation is that laboratory detection of serum steroid level was not done in this study to evaluate the systemic absorption of steroids in both groups although it was found to be within normal in other studies. Finally, more than three injections were not tried in this study which was found to be more effective in some refractory cases in other studies in which response was noted after four and five injections.

\section{Conclusion}

Intrapolyp steroid injection is an effective, easy, and safe procedure with short-lasting effect for at least 3 months. It was proven to show comparable results to oral steroids as both modalities showed a statistically significant improvement subjectively and objectively. However, cases with extensive bulky polyposis were resistant to complete eradication by injection and they may need surgical intervention later on.

\section{Acknowledgements}

Not applicable

\section{Authors' contributions}

SM contributes with the idea of the study and putting the methods and writing the paper and performing the submission process. ME and MS contribute with application of clinical steps of the methods on the patients and supervising the study work. AE contributes with application of clinical steps of the methods on the patients and data collection. All authors have read and approved the manuscript.

\section{Funding \\ None}

Availability of data and materials

Data are available from the corresponding author on reasonable request.

Ethics approval and consent to participate

This study has been approved by the ethical committee of the ENT

Department, Cairo University.

Reference number: Not applicable in our institute

Written informed consent forms were obtained.

Consent for publication

Written informed consents were obtained.

\section{Competing interests}

The authors declare that they have no competing interests.

Received: 14 October 2020 Accepted: 27 November 2020

Published online: 14 December 2020

\section{References}

1. Antunes M, Becker S (2010) The role of local steroid injection for nasal polyposis. Curr Allergy Asthma Rep 10:175-180

2. Ferguson B (1997) Nasal steroid sprays and septal perforations. Ear Nose Throat J. 76:75-76

3. Alobid I, Benitez P, Bernal M, Bernal-Sprekelsen M, Roca J, Alonso J, Picado C, Mullol J (2005) Nasal polyposis and its impact on quality of life: comparison between the effects of medical and surgical treatments. Allergy 60:452-458

4. Kiris M, Muderris T, Yalçıner G, Bercin S, Sevil E, Gul F (2016) Intrapolyp steroid injection for nasal polyposis: randomized trial of safety and efficacy. Laryngoscope 126:1730-1735

5. Hopkins C, Browne JP, Slack R, Lund V, Brown P (2007) The Lund-MacKay staging system for chronic rhinosinusitis: how is it used and what does it predict? Otolaryngol Head Neck Surg 137:555-561

6. Semenov $H$ (1952) The pathology of the nose and paranasal sinuses in relation to allergy. $\operatorname{Tr}$ Am Acad Ophth Otol 56:121-170

7. Myers D (1958) Experiences in the treatment of the allergic nasal polyp by the intrapolyp injection of prednisolone T.B.A. Laryngoscope 68:1-17

8. Wall J, Shure N (1952) Intranasal cortisone; preliminary study, A.M.A. Arch Otol 56:172-176

9. Moss W, Kjos K, Karnezis T, Lebovits M (2015) Intranasal steroid injections and blindness: our personal experience and a review of the past 60 years. Laryngoscope 125:796-800

10. Baker D, Strauss B (1962) Intranasal injection of long acting corticosteroids. Ann Otol Rhinol Laryngol 71:525-531

11. Simmons M (1960) Intranasal injection of corticosteroids. Calif Med 92:155-158

12. Ulku T, Levent S, Barlas A, Fuat K, Cagatay A (2003) The effectiveness of steroid treatment in nasal polyposis. Auris Nasus Larynx 30:263-268

13. Camp C, Clement P (1993) Results of oral steroid treatment in nasal polyposis. Rhinology 32:3-9

14. Thibaut V, Gevaert P, Holtappels G, Beule A, Wormald P, Mayr S, Hens G, Hellings P, Ebbens F, Fokkens W, Cauwenberge P, Bachert C (2010) Oral steroids and doxycycline: two different approaches to treat nasal polyps. Allergy Clin Immunol 125:1069-1076

15. Mabry R (1979) Intranasal corticosteroid injection: indications, technique and complications. Otolaryngol Head Neck Surg 87:207-211

16. Hager G, Heise G (1962) A severe complication with permanent practical blindness of one eye following intranasal injection. HNO 10:325-328

\section{Publisher's Note}

Springer Nature remains neutral with regard to jurisdictional claims in published maps and institutional affiliations. 